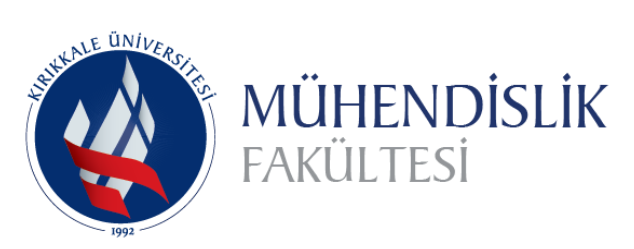
Uluslararası Mühendislik
Araştırma ve Geliştirme Dergisi UMAGD, (2022) 14(1), 338-346.
International Journal of
Engineering Research and
Development
10.29137/umagd.1004275

Cilt/Volume:14 Sayı/Issue:1 Ocak/January 2022

Araştırma Makalesi / Research Article

\title{
PLC Kontrollü Glove Box Tasarımı ve Atmosferindeki Oksijen Seviyesinin Kontrolü
}

\section{PLC-Controlled Glove Box Design and Control of the Oxygen Level in the Glove Box Atmosphere}

\author{
Mustafa Doğan ${ }^{1}$ iD \\ ${ }^{1}$ Kırıkkale Üniversitesi Bilimsel ve Teknolojik Araştırmalar Uygulama ve Araştırma Merkezi Müdürlüğü, 71450, Kırıkkale, TÜRKIYYE
}

Başvuru/Received: 04/10/2021ＫKabul/Accepted:30/01/2022Ｃ̧evrimiçi Basım/Published Online: 31/01/2022

Son Versiyon/Final Version: 31/01/2022

\begin{abstract}
$\ddot{O} z$
Glove-box sistemleri yaşadığımız atmosfer ortamından, deney yapılacak ortamın atmosferini yalıtır. Bu tip kapalı sistemler sızdırmazlık sağlayarak deney yapılan içerideki atmosferi dışarıdan tamamen izole eden bir yapıya sahiptir. Ayrıca glove-boxlar şeffaf bir yapıya sahip olduğundan dolayı içeride yapılacak deneylerin ve testlerin dışarıdan izlenmesine de imkân vermektedir. Uzun kollu eldiven kullanılarak eldiven kutusu içinde devam eden deneye müdahale edilebilmesi; kontrollü atmosfer içinde kapsamlı deneyler yapılabilmesini de mümkün kılmaktadır. Batarya üretim hatlarında, mesela lityum benzeri oksijen içeren ortamlarda alev alabilen kimyasallar kullanıldığında ya da OLED (organik ışık yayan diyot) üretim ve testinin sorunsuzca yapılabilmesi için düşük oksijen atmosferine sahip glove-box sistemlerinin kullanılması gereklidir. Bu sistemlerin en basit yapıda olan; atmosfer kontrol sistemi içermeyen ürünlerin fiyatları 20 bin euro seviyesinden başlamaktadır. İçerideki atmosferde bulunan oksijen seviyesi kontrol edilebilen ürünlerin fiyatları ise 100 bin euro üzerindeki fiyat seviyelerine kadar çıkmaktadır. Bu kapalı sistemde iç ortamın oksijen seviyesinin devamlı aşağıya çekilebilmesi için periyodik olarak iç atmosfer havasını vakumla boşaltan ve ardından iç atmosfere inert argon gazı verebilen PLC kontrollü bir sistem tasarlanmıştır. Elektrokimyasal oksijen sensörü ve ölçü aleti (multimetre) kullanılarak glove-box iç atmosferindeki oksijen seviyesi istenildiği zaman kullanıcı tarafından kontrol edilebilmektedir.
\end{abstract}

\section{Anahtar Kelimeler}

"Glove box, Oksijen sensör, PLC kontrol, Elektrokimyasal sensör”"

\begin{abstract}
Glove-box systems have a special structure which insulates the environment in which the experiments will be conducted from the atmosphere in which we live. In addition, glove-boxe systems have a transparent structure, which allows you to monitor the experiments and tests to be carried out inside at any time. Glovebox systems give ability to intervene the on going experiment in the glove box manually controlling using long-sleeved gloves. Also it makes possible to conduct extensive difficult experiments in this controlled atmosphere. For example lithium battery production lines, oxygen sensitive flammable chemical related experiments also OLED(organic light emitting diode) test and production levels must be done smoothly for the production of controlled low-oxygen atmosphere with the use of a glove box system is a necessity. In the market the simplest of these systems of devices without an atmosphere control system start at the level of 20 thousand euros and atmospheric controlled ones prices' reach to the levels above 100 thousand euros. In this system, a system that can periodically vacuum and periodically deliver inert argon gas inside is designed so that the oxygen level of the indoor environment can be continuously lowered. Atmospheric oxygen level inside the glove box was tracked, by measuring an electrochemical oxygen sensor' galvanometric current with a multimeter.
\end{abstract}

Key Words

"Glove Box, Oxygen sensor, PLC control, Electrochemical sensor" 


\section{Giriş}

İlk olarak 1940 yıllarında atmosfer kontrolüne de imkân veren Glove Box (Eldiven Kutusu) sistemleri askeri amaçlı olarak radyoaktif materyalleri incelemek için kullanılmıştır (Vauchy ve ark. 2021). Bu özel kontrollü atmosfere sahip ortam gereksinmelerinden dolayı özellikle ilaç sanayi, farmasotik, patojenler ve virüsleri kontrol altında tutmak için kullanıldı̆̆ında popularitesi zamanla daha da artmıştır. Günümüzde yariletken teknolojisinden ilaç sanayine kadar birçok sektörde amacına yönelik olarak farklı glove-box sistemlerinin üretimleri yapılmaktadır (Petrova ve ark. 2019, Szolga ve Stan 2021, Kumar ve ark. 2010).

Atmosfer kontrollü sistemde özellikle üzerinde çalışılacak olan elektronik yariletken yapılara zarar vermesi sözkonusu olduğunda oksijen ve nem miktarı mutlaka kontrol altında tutulması gereken parametrelerdir (Liu ve ark. 2020). Lityum pillerin paketlenmesinde özellikle lityum elementinin oksijen ile reaksiyona girme ve patlama tehlikesinden dolayı yine glove box sistemleri batarya üretim hatlarında da kullanılmaktadır (Kerlau ve ark. 2007). OLED (Organik Lüminesans Emisyonlu Diyot) üretiminde de oksijen ve nemin ortamda olması bu yapılara üretimde ve sonrasında zarar vermektedir. Üretilen OLED cihazının oksijene maruz kalma süresi ile orantılı olarak çalışma ömrü de kısalmaktadır (Doğan. 2021, Pal ve ark. 2021). OLED yüzeyinin kaplanması ve test edilmesi aşamalarında, ayrıca oksijen sensörünün test aşamalarında; bu tasarlanan glove box sistemi verimli bir şekilde referans verilen ilgili akademik çalışmalarda kullanılmıştır (Doğan. 2021, Doğan ve ark 2021). Bu kontrollü atmosfer şartlarında çalışılması güvenli bir çalışma ortamı sağlamasının yanında, ürünlerin arıza yapma olasılığını da düşürmektedir. Patlayıcı ve zehirli olan gazların algılama sensörü geliştirilmek istendiğinde yine bu atmosfer kontrollü glove box sisteminin kullanılması bir gerekliliktir (Fedorova ve ark. 2021).

Ultraviole ışınlar birçok deney cihazının içinde ve yaşlandırma deney düzeneklerinde de sıklıkla kullanılmaktadır (Doğan. 2020, Lee ve ark.2021, Doğan. 2021). Glove-box sisteminin yapıldığı plexiglass şeffaf olarak görünür bölgedeki ışığı geçirebilmektedir. Fakat ultraviyole bölgedeki ışığı geçirmediğinden gözlere zararlı olan bu ışığı bloke ederek dışarı çıkmasını engelleyebilmektedir (Zhou ve ark. 2005, Kucenic ve ark 2002, Frohn ve ark 2001). Glove box sisteminin duvarları plexiglass malzemeden üretildiği için,glove-box içinde yapılan ultraviyole ışınlama deneyleri kullanıcının gözlerinin zarar görmesini de engellemektedir (Spyratou ve ark 2021).

BAP projesi kapsamında alınan destek ile bu cihazın iç atmosfer kontrolü için oksijen sensörü temin edilmiş ve bu sistemin iç atmosferindeki oksijen seviyesinin kontrolü için kullanılmıştır. Tasarlanan glove box sistemi yerli imkânlar ile 20mm kalınlığında tamamen şeffaf olan plexiglass malzemeden yapılmıştır. Sistemin teknik çizimleri Solid Work katı model çizim programı kullanılarak tamamlanmıştır. Plexiglass levhalar hizmet alımı olarak sanayide imal edilmiştir. Plexiglass malzemenin yapıştırılması ve birleştirilmesinde çok verimli olduğu görülen ve birleştirilen ara yüzeylerde akıcı özelliği sahip olan cyanoacrylate yapıştırıcılar kullanılmıştır. Bu şekilde çok sağlam bir sızdırmazlık sağlanmıştır. Havadaki nem ve oksijen yüzde olarak miktarını gösteren dijital laboratuvar tipi nem ve sıcaklık ortam dedektörleri de kullanılmıştır. Ortam atmosferi çalışma öncesi ve sonrası denetlenerek karşılaştırılmıştır. İçerideki havayı vakumlaması için kullanılacak olan vakum pompası senkronize olarak azot gaz girişini sağlayan selenoid vanalar ile dönüşümlü bir şekilde birlikte çalıştırılarak içeride oluşturulan izole atmosferin kısa sürede uygun olan düşük oksijen $(<\% 1)$ seviyelerine gelmesi sağlanmıştır.

\section{Materyal ve Yöntem}

Solidwork yazılım programında üç boyutlu çizimleri yapılarak cihazın dış tasarımı ve dışarıdan görünümü oluşturulmuştur (Şekil 1, Şekil2). Glove box sistemi için 20mm kalınlığında şeffaf plexiglass levhalar Şekil1'de Solidworks de çizimi yapılan şemaya göre hazırlanarak temin edilmiştir. Sisteme ait selenoid açma ve kapama vanaları büyük "A" kısmı üzerine inert gaz girişi ve vakum gaz çıkışı olarak iki adet, ayrıca küçük olan bölme "B" üzerinde de inert gaz girişi ve vakum gaz çıkışı olarak iki adet olmak üzere toplam dört adet selenoid vana takılmıştır. Sistemin tamamlanmış hali Şekil 3'de görülmektedir. Sistemin bütün gaz giriş vanalarının açılma ve kapatılma kontrolleri Siemens LOGO PLC otomasyon modülü kullanılarak yapılmıştır. PLC otomasyonu sinyal giriş(input) olarak 2 adet ayrı açılıp kapanan anahtar ile sağlanmıştır. PLC cihazı ile her iki bölmenin bağımsız olarak atmosfer seviyesinin kontrol edilmesi amaçlanmıştır. Gaz giriş basıncı 1 bar olacak şekilde maksimum 200 bar basınca sahip \%99,999 saflıkta argon gazı içeren tüp üzerinden ayarlanmıştır. Vakum pompası olarak düşük maliyetli olan ama çekiş gücü fazla olan, dakikada 2,5 litre hava emiş gücüne sahip HAILEX marka diyaframlı akvaryum pompası (sızdırmaz plastik bir kutu içine konularak) sistemin her iki bölmenin de vakumunu almak amaçı kullanılmıştır. Bu şekilde vakum pompası alım maliyeti de düşürülmüştür.

Sistem ilk tamamlandığında kaçak kontrolü şu şekilde yapılmışır. Bölme içine bir miktar çakmak gazı (patlayıcı ve yanıcı gaz) verilerek ve içerde eldivenlere baskı yapılarak mbar seviyesinde pozitif iç basınç oluşturularak ek bağlantı noktalarında kaçak olup olmadığının tam bir kontrolü yapılmıştır. Bu amaçla ppm seviyesinde hassasiyetle içerden sızabilecek patlayıcı ve yanıcı gaz miktarını ölçebilen Sensit HXG3 gaz algılama cihazı kullanılarak kontroller yapılmışır. Bulunan kaçak olan sızıntı noktaları tekrardan silikon ve cyanoacrylate türü yapıştırıcılar ile kapatılmıştır.

Bütün sistem 220 volt ile çalışan PLC sistemi baz alınarak şebeke gerilimi ile çalışacak şekilde seçilmiştir. Bu şekilde aynı zamanda ayrıca adaptör ve güç kaynakları kullanımına da gerek kalmamıştır. İçeride azaltılması düşünülen oksijen seviyesi PLC kontrollü hava 
boşaltma ve doldurma sistemi ile oksijen seviyesi azaltılarak ortamdan oksijenin yüzde 99'u uzaklaştırılana kadar glove box sistemi çalıştırılmıştır. Sistemin verimli bir şekilde çalışabildiği; oksijen sensöründen alınan veriler ile de kontrol edilerek doğrulanmıştır.

\section{Sonuçlar ve Tartıșma}

PLC otomasyon sistemi Şekill'de görüldüğü gibi bir yapıya sahiptir. 8 adet giriş ve 4 adet röle çıkışına sahiptir. Sistem içerisine iki adet farklı zamanlayıcı programlanmıştır. Birinci zamanlayıcı program aktif hale gelmesi için giriş 2 (INPUT2) üzerine bir sviç vasıtası ile 220 volt gerilim gönderilerek yapılır. Argon gaz çıkışı bir debimetre ile ölçülerek 9 litre/dakika akış hızına sahip olduğu görülmüştür. Vakum sisteminin gaz akış seviyesi ölçüldügünde gaz vakum çıkışının 2,5 litre/dakika akış hızında olduğu görülmüştür. Birinci zamanlayıcı 4 saniye süre ile gaz girişini açmaktadır ve 14 saniye süre ile vakum pompası çıkışını açmaktadır. Toplam vakum yapılan gaz hacmi ile toplam akan inert gaz hacminin miktarının yaklaşık eşit bir rakamda olması sağlanmıştır. 36 litre gaz girişine karşıllık yaklaşık 35 litre gaz vakumu yapılmaktadır.

Küçük bölme için vakum sisteminin gaz çekiş gücü ölçüldüğünde gaz vakum girişinin 1,25 litre/dakika akış hızında olduğu görülmüştür. Bunun sebebi büyük olan A prizması içinde ek olarak bir vakum pompası daha iç kısımda kullanılmasıdır. Argon gaz akış hızı küçük bölme içinde aynıdır. Bu A bölmesi içinde 4 saniye süre ile inert gaz girişi açılmaktadır ve 25 saniye süre ile vakum pompası gaz çıkışı açılmaktadır. 37,5 litre vakum gaz çıkışına karşılık küçük bölme için 36 litre argon gaz girişi olmaktadır.

Bu vakum süresi ve gaz giriş süresi zaman parametreleri PLC otomasyonu üzerinden PLC'yi tekrar programlamaya gerek kalmadan üzerindeki tuş takımı ile de değiştirilebilmektedir. Şekil 2'de görülen B sisteminin dışarısı ile olan kapak bağlantısı ve A bölmesi ile olan her iki kapak bağlantısının sıkıca kapanabilmesi için dört köşesine ayrıca 2,5 santimetre çapında ve $0,5 \mathrm{~cm}$ kalınlığında neodyum mıknatıslar karşılıklı olarak yerleştirilmiştir. Bu şekilde eldiven ile iç atmosferde deney yapılırken A bölmesi içindeki kapağın sıkıca otomatik olarak kapanması da sağlanmaktadır. Araya yerleştirilen o-ring kauçuklar tam olarak iki bölme arasında ortam sızdırmazlığını da sağlamaktadır. Şekil 2 ve Şekil 3 incelendiğinde B ara bölmesi malzeme aktarımında büyük kolaylık sağlamaktadır. B bölmesi oksijen seviyesi kısa sürede aşağıya çekilebilmektedir ve büyük A bölmesinin düşük oksijen seviyesine sahip olan atmosferinin malzeme aktarımı esnasında çok fazla etkilenmemesi de sağlanmıştır.

Elektrokimyasal oksijen sensörü sıvı elektrolit içeren bir yapıya sahiptir (Şekil 4a, 4b). Bu yüzden dolayı bu sensörün ömrü birkaç senedir. Sensörün ömrü; sensör içindeki sıvı kimyasalın ölçülen gaz ile etkileşime girerek işlevini yerine getiremeyeceği bir zamana ulaşana kadar devam eder (Şekil 4). Bu sensör kimyasalı havadaki gaz ile etkileşime girerek belli bir seviyede akım değeri oluşturur Oksijen sensörü galvanometrik prensiple çalıştığından kalibrasyona da gerek duymamaktadır. Galvanometrik bir yapıya sahip olduğu için sensör üzerinden geçen mikroamper seviyesinde olan akım değeri ölçülerek oksijen seviyesine verdiği tepki multimetre üzerinden ölçülebilmektedir (Şekil 4c). Bu akım seviyesinin karşılık geldiği oksijen seviyesinin yüzde kaç oksijene karşılık geldiğini bulmak için endüstriyel Sensit G2 gaz algılama detektörü kullanılarak bir ölçüm tablosu oluşturulmuştur (Şekil 5 ve Tablo 1). Yüzde 21 değerinden yüzde sıfır değerine kadar oksijen seviyesi aynı kapalı kontrollü ortamda düşürülmüştür. Yüzde 21 ve yüzde sıfır oksijen aralığında toplam 111 farklı mikroamper seviyesinde ölçülen akım değerlerine karşılık gelen oksijen yüzde değerleri kaydedilmiştir. Bu çalışma içinde oksijen seviyesinin yüzdesini belirlemede bu elde edilen veriler kullanılmıştır (Şekil 5 ve Tablo 1). 


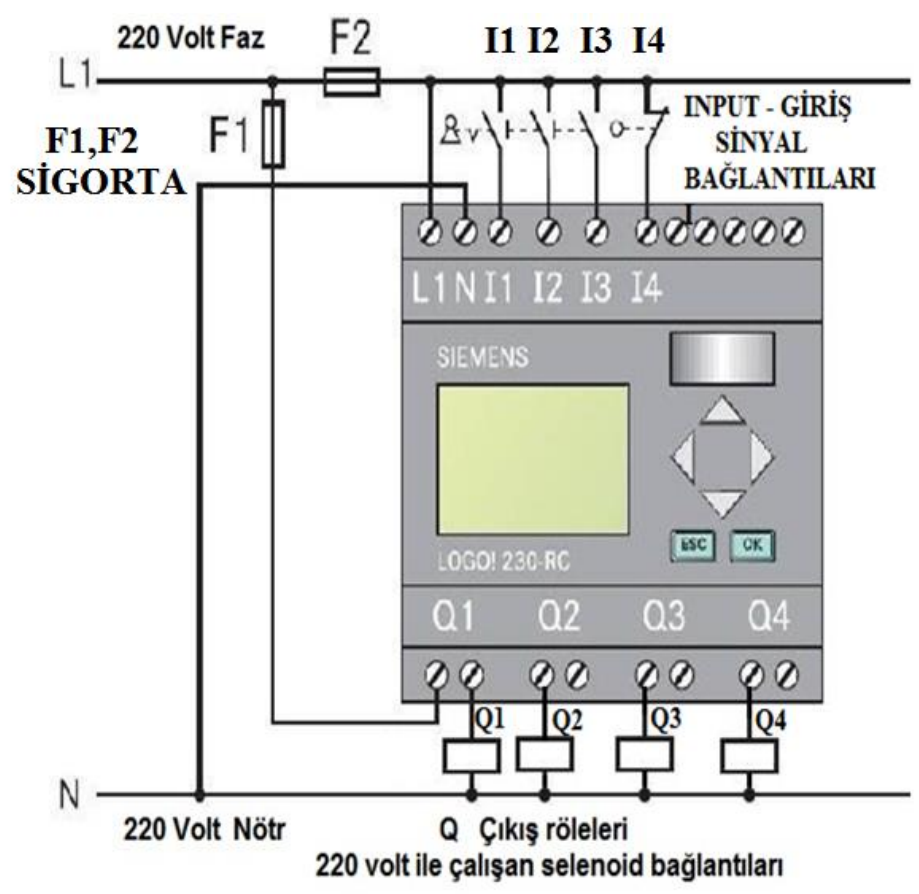

Şekil 1. Siemens logo PLC ile kurulan otomasyon sistemin giriş ve çıkış bağlantıları şu şekildedir. I2(INPUT) giriş üzerine bağlanan sviç büyük dikdörtgen prizma atmosfer zamanlayıcı programını başlatmaktadır. I4 (INPUT) girişi üzerine bağlanan sviç küçük küp prizma atmosfer zamanlayıcı programını başlatmaktadır. I1 (INPUT) ayak pedalı ile çalışır ve B bölmesi vakum girişini manuel olarak açar. I3(INPUT) ayak pedalı ile çalışır ve B bölmesi gaz girişini manuel olarak açar. Q1 çıkışı B bölmesi vakum girişi selenoidini açmaktadır. Q2 çıkışı B bölmesi gaz giriş selenoidini açmaktadır. Q3 çıkışı A bölmesi vakum girişi selenoidini açmaktadır. Q4 çıkışı A bölmesi gaz giriş selenoidini açmaktadır.

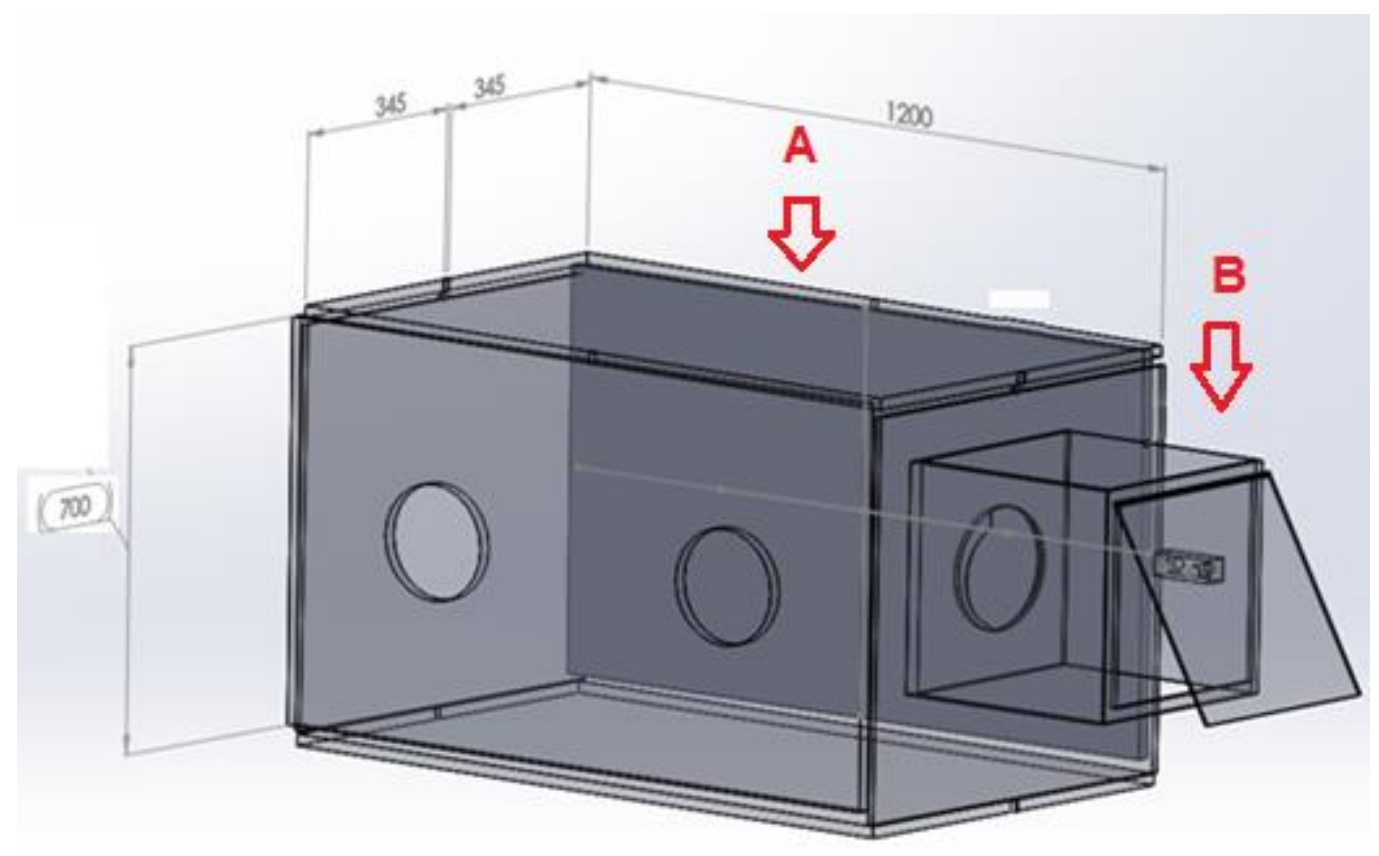

Şekil 2. Üretilen glove box sisteminin Solidwork programı ile üretimi öncesi çizilmiş olan genel olarak boyutlarını gösteren şekil 


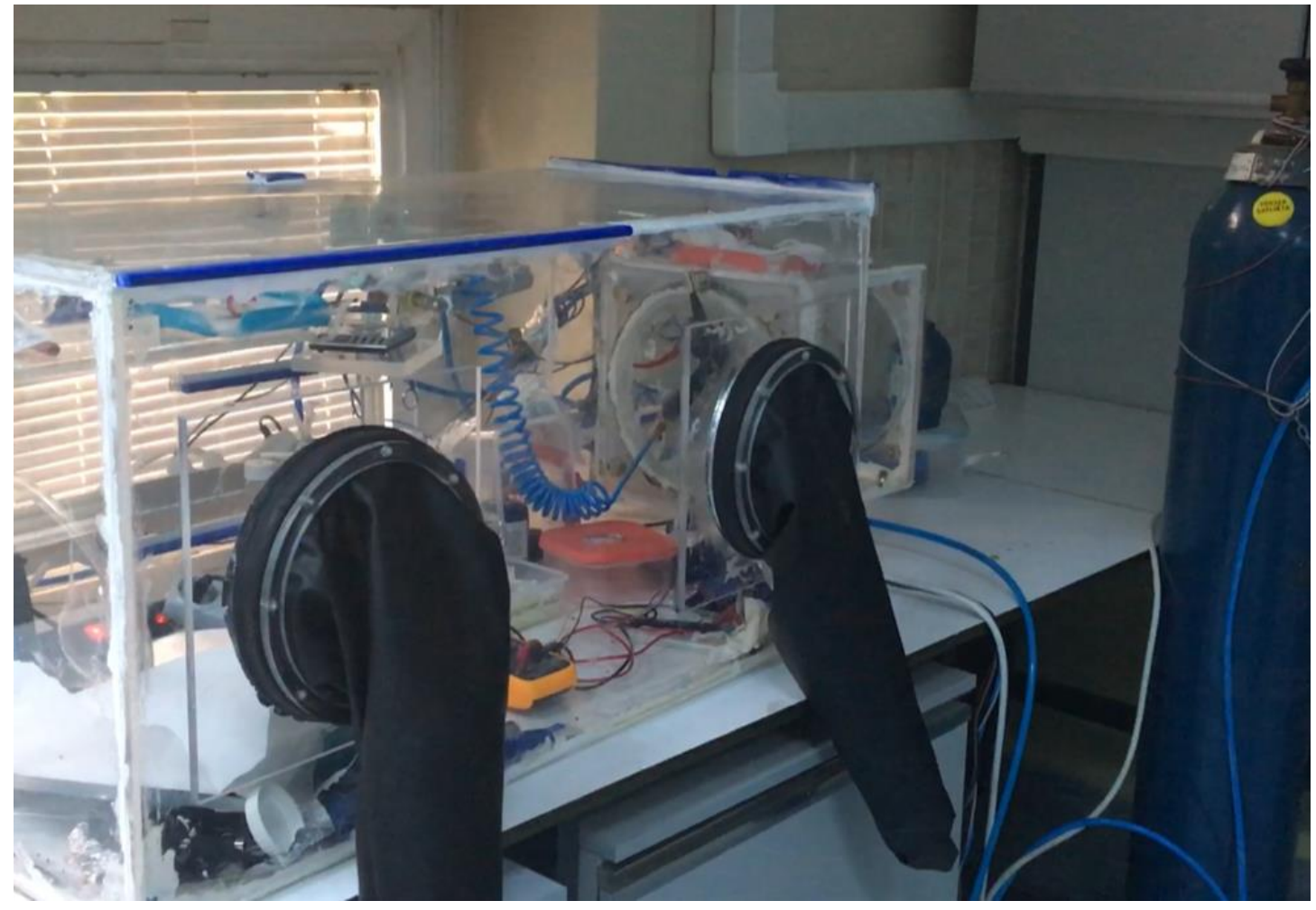

Şekil 3. Üretimi tamamlanan glove box sistemine ait resim görülmektedir.

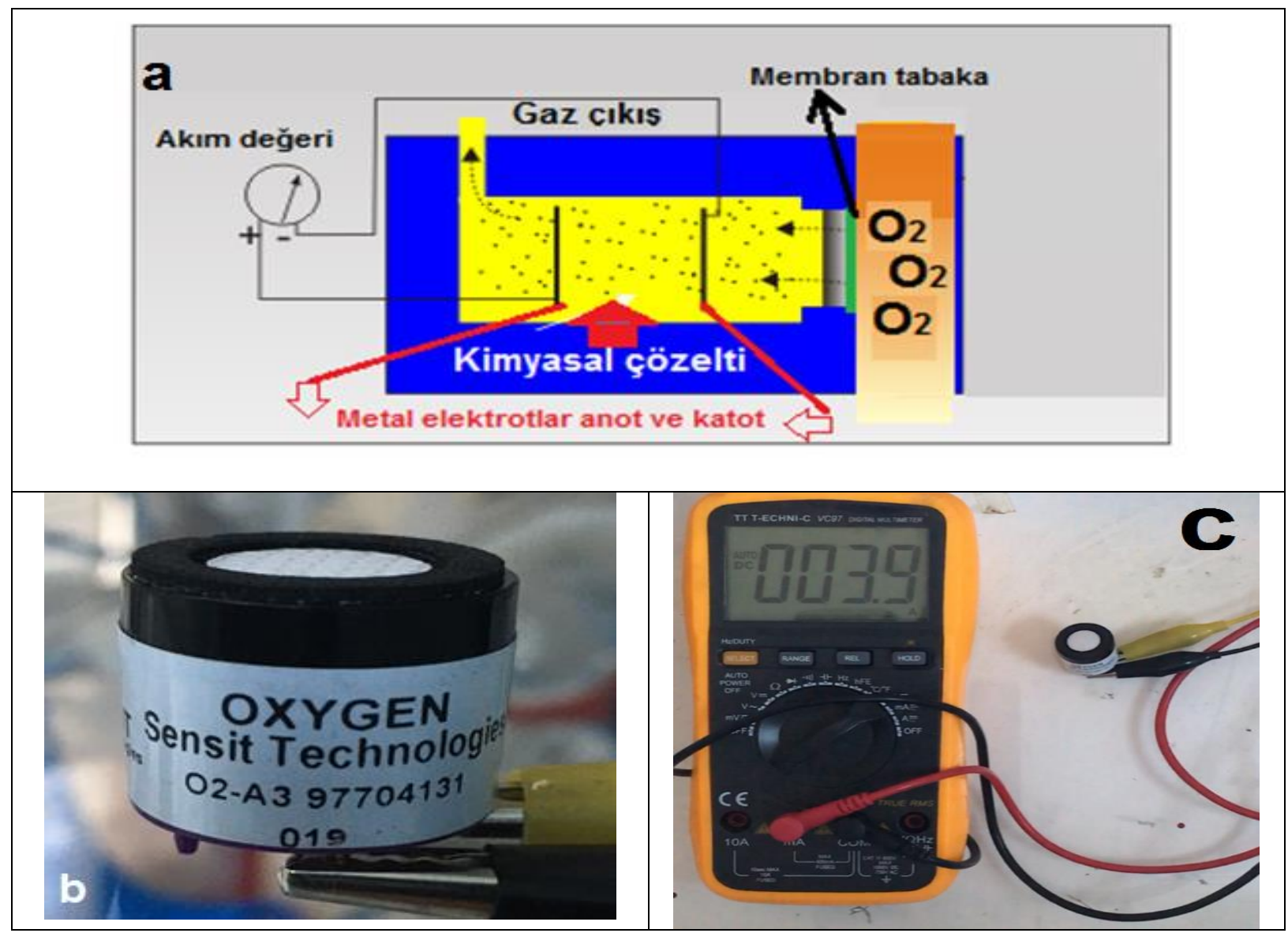

Şekil 4. (a) Elektrokimyasal sensörün çalışma sistematiğini gösteren çizim (b) kullanılan elektrokimyasal oksijen sensörünün resmi (c) glove box içinde ölçü aleti (multimetre) kullanılarak elektrokimyasal sensörünün akım değerleri ile gaz ölçümü yapılması 


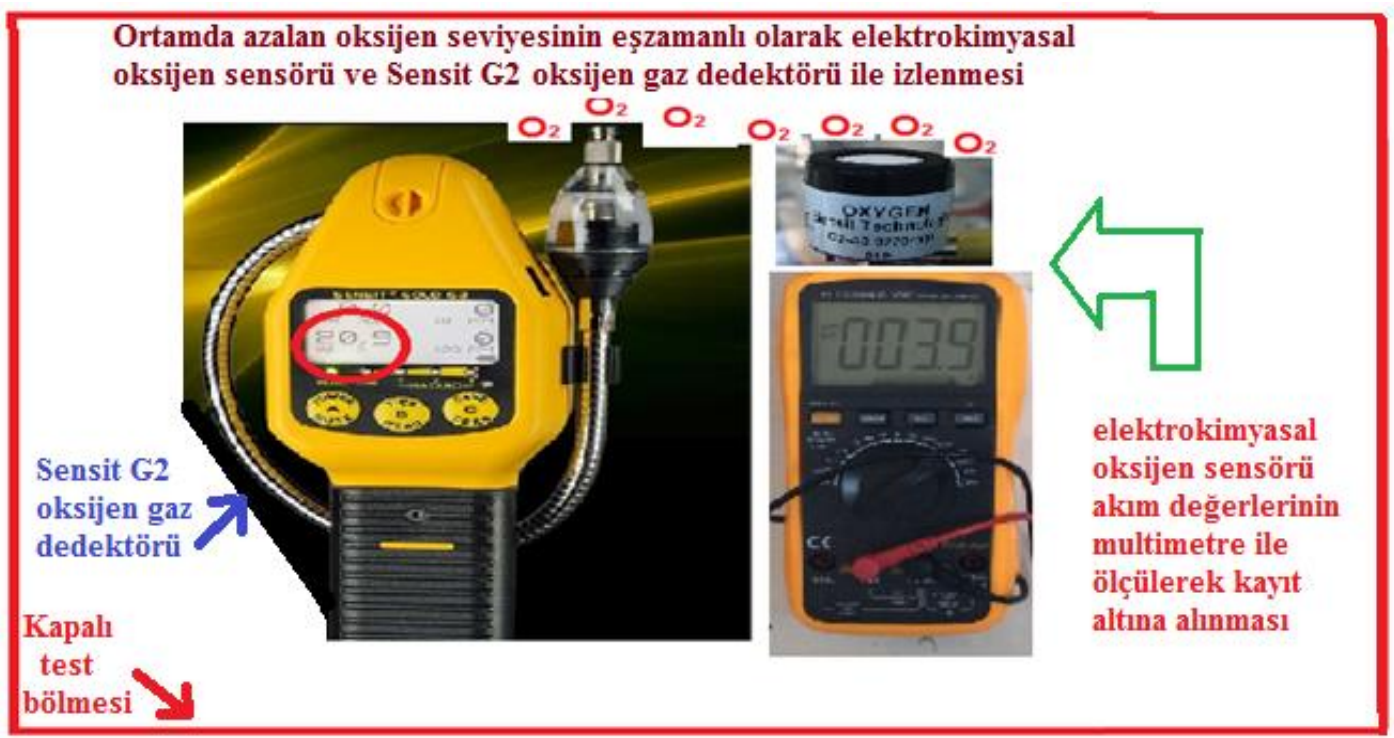

Şekil 5. Kapalı bölme içerisinde oksijen seviyesi düşürülerek Sensit G2 gaz dedektörü ve oksijen sensörü aynı anda çalıştırılarak düşen oksijen yüzdelerine karşılık gelen akım değerleri oksijen gaz seviyesi ölçümünde kullanmak için kayıt altına alınmıştır.

\section{Bulgular ve Tartışma}

Cihaz içindeki bölmeler içindeki oksijen seviyesi elektrokimyasal sensörden alınan akım değeri olarak zamana bağlı olarak grafiğgi şekil 6'da çizilmiştir. 0,588 metreküp hacme sahip olan büyük dikdörtgen A prizması içinde 20 saniyelik periyot içinde 4 saniye gaz girişi (9 litre /dakika) ve 16 saniye vakum gaz çıkışı (2,5 litre/ dakika) uygulanarak 70 dakika sürenin sonunda oksijen seviyesi yüzde 1,3 değerlerine ulaşmıştır. Şekil 6 ve Şekil 7'de bulunan grafikler incelendiğinde oksijen miktarı aşağı seviyelere düştükçe oksijen seviyesinin düşme hızında da azalma olduğu görülmektedir. Bunu şu şekilde açıklayabiliriz. Oksijen seviyesinin yüzde 21 seviyesinden yüzde 10 seviyesine düşme süresi 10 dakika sürmüştür. Yüzde 21 seviyesinden yüzde 2,5 seviyesine düşmesi ise 40 dakika sürmüştür. Eğer oksijen seviyesi aynı sürede yarısı seviyesine düşme gerçekleşmiş olsa; bu değerin 30 dakika olması gerekirdi.

0,022 metreküp hacme sahip olan küçük küp B prizması içinde 29 saniyelik periyot içinde 4 saniye gaz girişi ( 9 litre /dakika) ve 25 saniye vakum gaz çıkışı (1,25 litre/ dakika) uygulanarak yaklaşık 20 dakika sürenin sonunda oksijen seviyesi yüzde 0,9 değerine ulaşmıştır. Şekil 7a da görüldüğü gibi oksijen seviyesi yüzde bir seviyelerine yaklaştığı halde 50. ve 70. dakika arasında oksijen seviyesi düşme hızı oldukça yavaşlamıştır. Oksijenin seviyesinin daha da aşağı seviyelere gelmesi için çok daha fazla zaman gerekmektedir (Tablo 1). Bunun sonucu olarak oksijen seviyesi ppm seviyelerine düşürülmek istenildiğinde çok daha uzun süre boyunca PLC kontrollü gaz tazeleme sisteminin çalıştırılması gerekmektedir.

Tablo 1. Glove box sisteminin A ve B bölmesi içinden elektrokimyasal oksijen sensörü kullanılarak alınan akım değerleri ve karşıllık gelen oksijen yüzdeleri

\begin{tabular}{cccccc}
\hline & A bölmesi & & \multicolumn{3}{c}{ B Bölmesi } \\
\hline Dakika & $\mu \mathrm{A}$ & oksijen yüzdesi & Dakika & $\mu \mathrm{A}$ & oksijen yüzdesi \\
\hline 0 & 63 & 21 & 0 & 63,4 & 21 \\
5 & 37,7 & 13 & 1 & 48,8 & 16,1 \\
10 & 26,2 & 9,7 & 2 & 32 & 11,7 \\
15 & 18 & 7,4 & 3 & 22,5 & 8,6 \\
20 & 12,2 & 5,7 & 4 & 15 & 6,4 \\
25 & 8,4 & 4,4 & 5 & 9,2 & 4,7 \\
30 & 5,8 & 3,6 & 6 & 6 & 3,7 \\
35 & 4,6 & 3,2 & 7 & 4 & 2,9 \\
40 & 2,9 & 2,5 & 8 & 2,7 & 2,5 \\
45 & 2,3 & 2,3 & 9 & 1,8 & 2,1 \\
50 & 2 & 2,2 & 10 & 1,3 & 1,9 \\
70 & 0,4 & 1,3 & 15 & 0,5 & 1,3 \\
& & & 20 & 0,1 & 0,9 \\
\hline
\end{tabular}




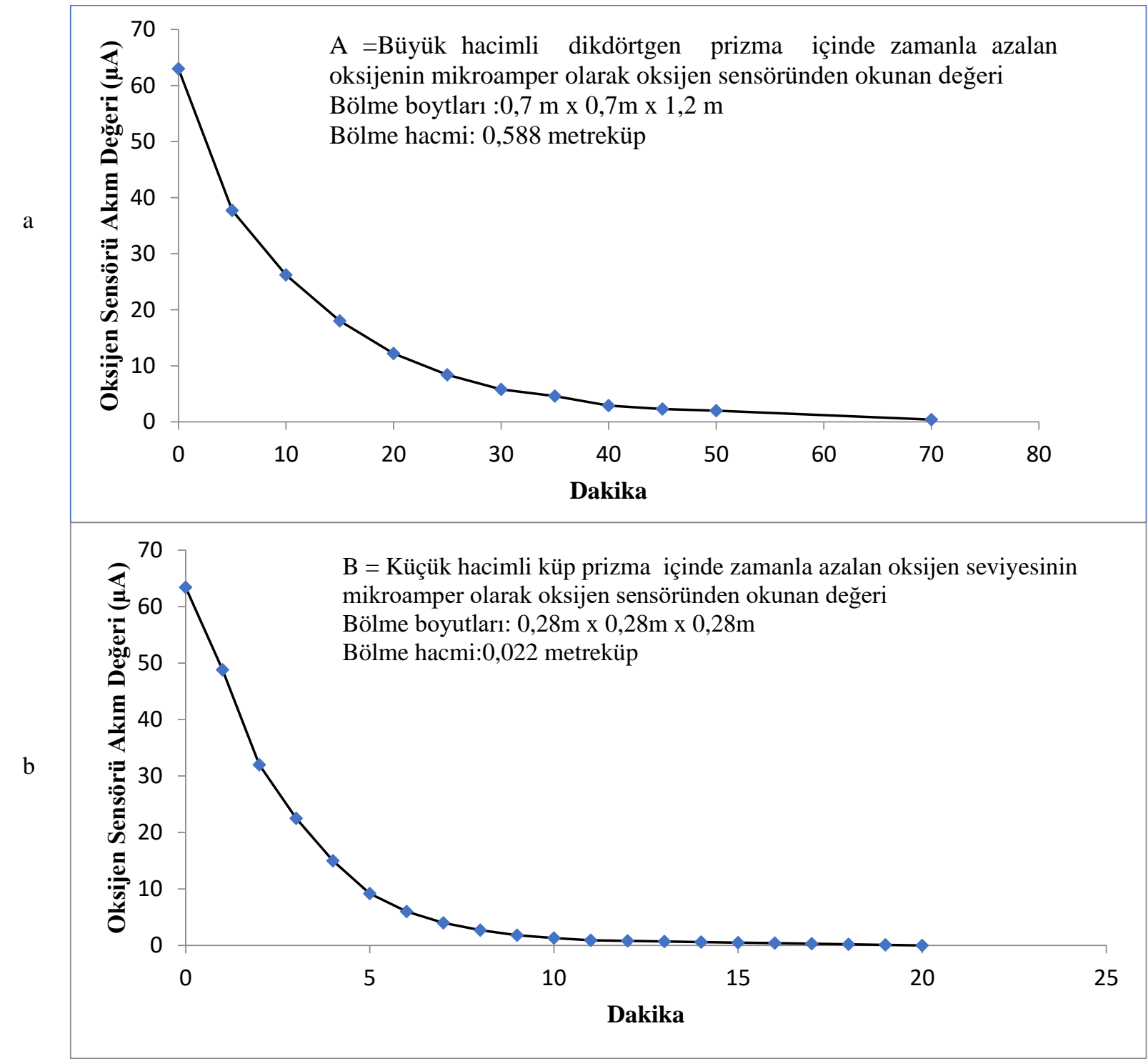

Şekil 6. (a) Sistem çalıştıktan sonra büyük prizma eldiven kutusu içinde zamanla azalan oksijenin miktarını gösteren elektrokimyasal sensör tepkisi (b) Sistem çalıştıktan sonra küçük küp prizma kutusu içinde zamanla azalan oksijenin miktarını gösteren elektrokimyasal sensör tepkisi 
a

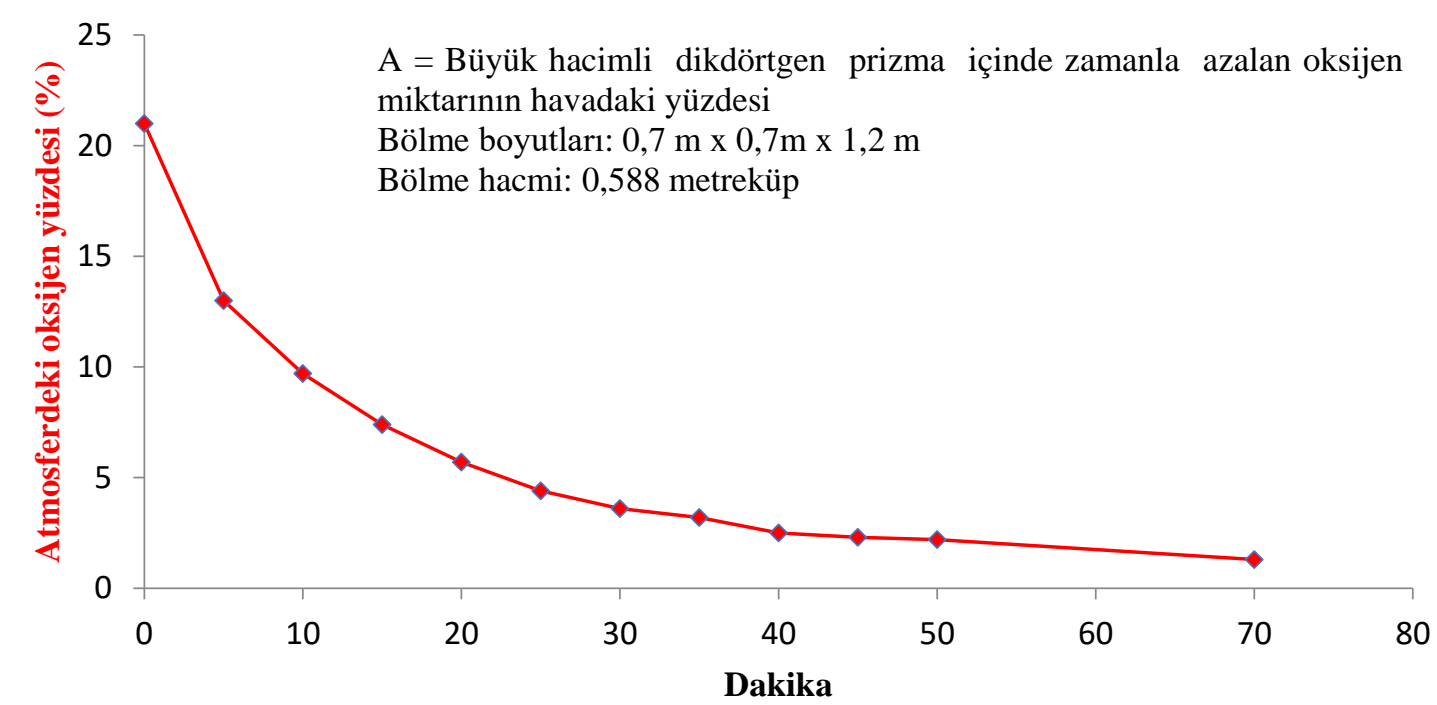

$\mathrm{b}$

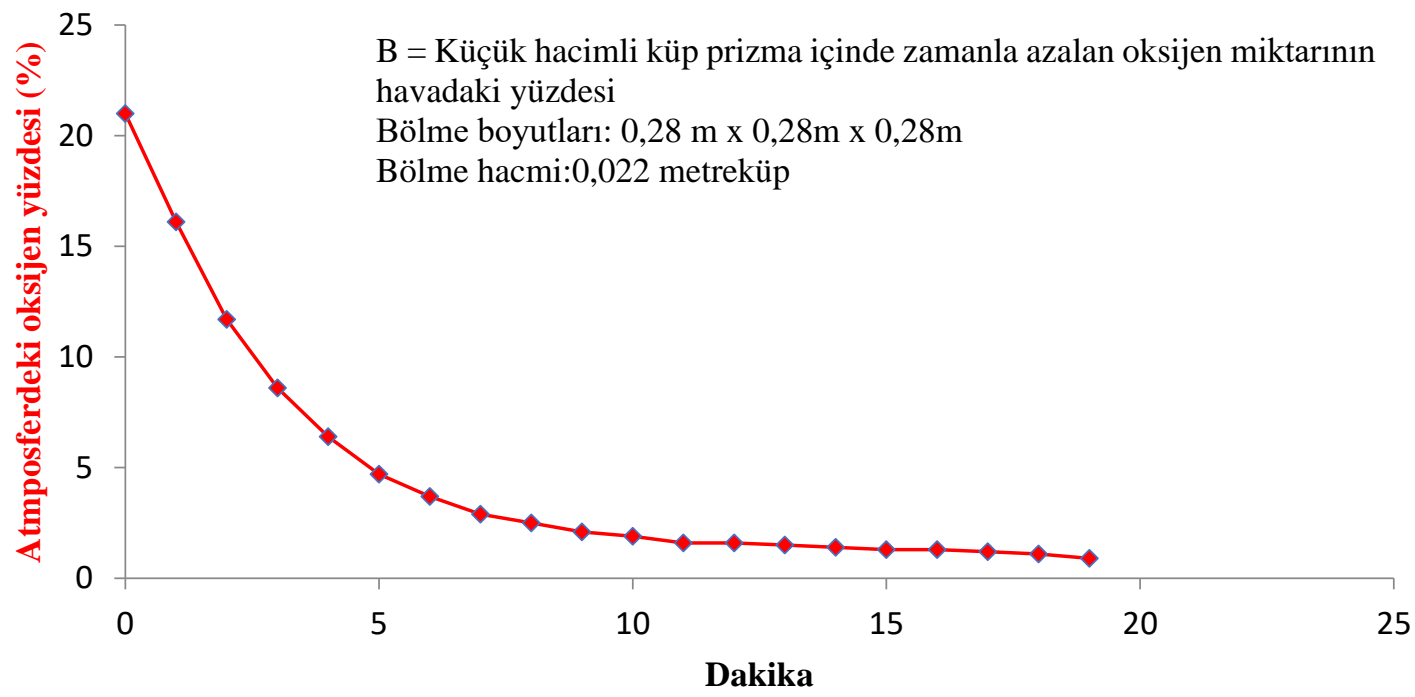

Şekil 7. a) Sistem çalıştıktan sonra büyük prizma eldiven kutusu içinde zamanla azalan oksijen miktarının yüzdesini gösteren grafik

b) Sistem çalıştıktan sonra küçük küp prizma kutusu içinde zamanla azalan oksijenin miktarının yüzdesini gösteren grafik

\section{Sonuç}

PLC kontrollü atmosfer kontrol sistemi sağlıklı bir şekilde çalışmıştır. PLC sistemindeki zaman parametreleri istenildiğinde tuş takımı üzerinden değiştirilebilmektedir. Elde edilen veriler incelendiğinde 0,588 metreküp hacmindeki bir dikdörtgen prizmanın oksijen seviyesinin sıfıra seviyesine doğru düşmesi 70 dakika sürmüştür. Küçük olan 0,022 metreküp hacmindeki küp prizmanın oksijen seviyesinin yüzde 0,9 seviyesine düşmesi ise yaklaşık 20 dakika sürede gerçekleşmiştir. Elektrokimyasal sensör ve multimetre yardımı ile oksijen seviyesinin kontrolünün rahatlıkla gerçekleştirilebileceği gösterilmiştir. PLC otomasyonu ve elektrokimyasal oksijen sensörü verileri kullanılarak sistemin maliyeti en az beşte bir seviyelerine kadar çekilmiştir. Buna benzer sistemlerin kolaylıkla tasarlanması için elde edilen veriler ve gaz seviyesi ölçüm yöntemi yol gösterici bir niteliğe sahiptir.

\section{Teşekkür}

Kırıkkale Üniversitesi Bilimsel ve Teknolojik Araştırmalar Uygulama ve Araştırma Merkezi Müdürlüğüne (KÜBTUAM) verdikleri destek ve yardımlar için teşekkür ederim. Ayrıca bu çalışmada cihazın montaj ve birleştirme aşamalarında, benden yardımlarını esirgemeyen Dr. Öğr. Gör. Ümit ERDEM arkadaşıma da teşekkür ederim. 


\section{Referanslar}

Doğan, M. (2020). Determining the lowest sulfur detection limit in diesel fuel by ultraviolet fluorescence. Phosphorus, Sulfur, and Silicon and the Related Elements, 196(1), 47-53.

Doğan, M. (2021). Polymer-layered oxygen sensor design and testing. Journal of Materials Science: Materials in Electronics, 1-11.

Doğan, M. (2021). Ultraviolet light accelerates the degradation of polyethylene plastics. Microscopy Research and Technique, 84( 11), 2774-2783.

Doğan, M., Erdem, Ü., \& Ökten, S. (2021). Production of organic light-emitting diode with fluorescence featured quinoline derivative. International Journal of Chemistry and Technology, 5 (2), 172-177.

Fedorova, A. A., Anishchenko, D. V., Beletskii, E. V., Kalnin, A. Y., \& Levin, O. V. (2021). Modeling of the overcharge behavior of lithium-ion battery cells protected by a voltage-switchable resistive polymer layer. Journal of Power Sources, 510, 230392.

Frohn, A., Dick, H. B., Augustin, A. J., \& Grus, F. H. (2001). Late opacification of the foldable hydrophilic acrylic lens SC60BOUV. Ophthalmology, 108(11), 1999-2004.

Kerlau, M., Marcinek, M., Srinivasan, V., \& Kostecki, R. M. (2007). Reprint of "Studies of local degradation phenomena in composite cathodes for lithium-ion batteries". Electrochimica Acta, 53(3), 1385-1392.

Kucenic, M. J., Patel, M., Feldman, S. R., Liguori, A., \& Fleischer, A. B. (2002). Visual discrimination testing of ultraviolet transmitting and ultraviolet blocking acrylic thermoplastics. Photodermatology, photoimmunology \& photomedicine, 18(5), 228-231.

Kumar, V. S., Kumar, R., Sivaraman, N., Ravisankar, G., \& Vasudeva Rao, P. R. (2010). Design and adaptation of a novel supercritical extraction facility for operation in a glove box for recovery of radioactive elements. Review of Scientific Instruments, 81(9), 094101.

Lee, S., Kim, S. H., Jo, Y. Y., Ju, W. T., Kim, H. B., \& Kweon, H. (2021). Effects of ultraviolet light irradiation on silk fibroin films prepared under different conditions. Biomolecules, 11(1), 70.

Liu, D. , QingXin, Z., YanQing, Y., HongFei, L., LiJia, C., QunLiang, S. (2020). Controllable Multistep Preparation Method for High Efficiency Perovskite Solar Cells with Low Annealing Temperature in Glove Box. Energy Technology, 8( 7), 2000071.

Pal, K., SI, A., Stephen, R., \& Thomas, S. (2021). Conductive Polymer Nanocomposites for Organic Light-Emitting Diodes (OLEDs). Handbook of Polymer and Ceramic Nanotechnology, 281-292.

Petrova, E. V., Avadhanula, V., Michel, S., Gincoo, K. E., Piedra, P. A., \& Anandasabapathy, S. (2019). Remote laboratory management: respiratory virus diagnostics. JoVE (Journal of Visualized Experiments), (146), e59188.

Spyratou, E., Antonakos, I., Kareliotis, G., Bacharis, C., \& Efstathopoulos, E. P. (2021). X-ray radiation affects the protection filter of yellow-tinted acrylic hydrophobic intraocular lenses against harmful UV-A and blue light. Hellenic Journal of Radiology, 6(3).

Szolga, L. A., \& Stan, C. A. (2021). Plexiglass glove box for organic solar cells. In IOP Conference Series: Materials Science and Engineering (Vol. 1032, No. 1, p. 012048). IOP Publishing.

Vauchy, R., Fouquet-Métivier, P., Martin, P. M., Maillard, C., Solinhac, I., Guéneau, C., \& Léorier, C. (2021). New sample stage for characterizing radioactive materials by $\mathrm{X}$-ray powder diffraction: application on five actinide dioxides $\mathrm{ThO} 2, \mathrm{UO} 2, \mathrm{NpO} 2, \mathrm{PuO} 2$ and AmO2. Journal of Applied Crystallography, 54(2), 636-643.

Zhou, S., Wu, L., Xiong, M., He, Q., \& Chen, G. (2005). Dispersion and UV-VIS Properties of Nanoparticles in Coatings. Journal of dispersion science and technology, 25(4), 417-433. 